\title{
Interventricular septal defect shown by left ventricular cine-angiocardiography
}

\author{
J. F. N. Taylor and A. R. Chrispin \\ From The Hospital for Sick Children, Great Ormond Street, London W.C.I
}

Defects in the interventricular septum have been shown in 63 patients by left ventricular cineangiocardiography. The technique shows with precision the single septal defect. When multiple

- defects are separated by an appreciable distance, they are also accurately shown. Such a demonstration of the site of the defect permits a predetermined surgical approach to closure.

This study was prompted by the need felt by our surgical colleagues for more accurate localization of the defect in the interventricular septum, as a high proportion of children undergoing operation for closure of these defects was noted to have large or multiple defects.

Defects in the interventricular septum occur both in the membranous and muscular parts of the septum, and they may be single or multiple. At surgical closure the approach is dependent on the site of the defect. The approach may be from the right atrium through the tricuspid valve, through the right ventricular wall, through the apex of the left ventricle, or through the aorta and aortic valve (Gerbode et al., 1958; Cooley, r959; Garamella et al., I960; Kay et al., r960;

- March et al., I96r ; Mustard, I96I ; Hudspeth et al., I962; Nicks et al., I962; Björk, I964, 1965; Kay, Rodriguez, and Zimmerman, I965; Reynolds, I966; Gonzalez-Lavin and Barratt-Boyes, I969).

Patients submitted for closure of an uncomplicated ventricular septal defect have a

shunt from the left ventricle through the defective septum and into the right ventricle.

- A septal defect with a shunt in this direction is commonly not shown directly by a right ventricular angiocardiogram. Later a shunt may be demonstrated when contrast medium recirculates through the heart. The site of the -defect in the septum is frequently not defined either early or late in the right ventricular angiocardiogram.

Since there is a shunt from the left ventricle across the defect, in patients in whom closure of the defect is contemplated advantage may

Received 7 July 1970. be taken of this shunt by an injection of contrast medium into the left ventricle.

This report evaluates the findings in 63 patients who were investigated by left ventricular cine-angiocardiography (Table I).

TABLE I 63 patients with defect in interventricular septum and indicating associated cardiac lesion

\begin{tabular}{ll} 
Associated cardiac lesion & $\begin{array}{l}\text { No. of } \\
\text { patients }\end{array}$ \\
\hline $\begin{array}{l}\text { Ventricular septal defect } \\
\text { Ventricular septal defect with pulmonary } \\
\text { stenosis }\end{array}$ & 38 \\
$\begin{array}{c}\text { Ventricular septal defect with atrial } \\
\text { septal defect }\end{array}$ & 5 \\
$\begin{array}{l}\text { Ventricular septal defect with persistent } \\
\text { ductus arteriosus }\end{array}$ & 5 \\
$\begin{array}{l}\text { Ventricular septal defect with aortic } \\
\text { regurgitation }\end{array}$ & 3 \\
$\begin{array}{l}\text { Ventricular septal defect with coarctation } \\
\text { of aorta }\end{array}$ & 2 \\
$\begin{array}{l}\text { Ventricular septal defect with aorto- } \\
\text { pulmonary window }\end{array}$ & 2 \\
$\begin{array}{c}\text { Double outlet right ventricle } \\
\text { Transposition and ventricular septal defect } \\
\text { Corrected transposition and ventricular } \\
\text { septal defect }\end{array}$ & I \\
\hline & I \\
\hline
\end{tabular}

Sixty of these patients had a left-to-right shunt at ventricular level. In three patients the pulmonary artery had been banded in infancy and there was a small right-to-left shunt. Surgical closure of the defective septum has been carried out in $\mathbf{2 8}$ patients, and it has been possible to check how accurately the technique can indicate the site and number of defects.

Conditions not included in this survey are tetrad of Fallot, persistent truncus arteriosus, and defects of the atrioventricular canal. 


\section{Clinical features and indications for investigation}

The age range of the patients studied varied between 3 weeks and 14 years (see Table 2), with one-third being infants (i.e. children less than I year of age). The remainder were older children, investigated before contemplated surgical closure of the ventricular septal defect.

\section{TABLE 2 Age distribution of 63 patients} studied

\begin{tabular}{ll}
\hline Age & $\begin{array}{l}\text { No. of } \\
\text { patients }\end{array}$ \\
\hline <6 months & 13 \\
6 months-1 year & 7 \\
1 year-3 years & 9 \\
3 years-6 years & 14 \\
6 years-10 years & 17 \\
> 10 years & 3 \\
\hline
\end{tabular}

All the infants investigated had remained in cardiac failure despite adequate medical treatment, and had failed to thrive. Investigation was therefore undertaken for diagnostic reasons, and also to assess whether, if a ventricular septal defect was present, banding of the pulmonary artery should be considered (Muller and Dammann, 1952; Stark et al., 1969). In this age-group access to the left ventricle was gained progradely through the mitral valve from the left atrium, when the atrial septum was patent. No arteriotomy was carried out in infancy specifically for left ventricular cine-angiocardiography.

In all the children investigated by left ventricular cine-angiocardiography the study was made before the anticipated surgical closure of the septal defects. The children studied in this way had a left-to-right shunt producing a pulmonary flow greater than twice that in the systemic circulation, apart from those patients who had had banding of the pulmonary artery carried out in infancy. One patient with transposition of the great arteries is included in this series. Whenever possible the left ventricle was catheterized through the mitral valve, the left atrium being entered by crossing the atrial septum, but in some instances (33 cases) it was necessary to carry out a femoral arteriotomy.

\section{Technique}

In all 63 patients left ventricular cine-angiocardiography was carried out as part of the investigation, immediately after the haemodynamic study, which was performed with the patient sedated, and usually sleeping quietly. In all instances angiography was performed with the patient anaesthetized; this has been found to be the safest and most satisfactory procedure for young patients at this hospital.

Where possible the catheter was introduced through the mitral valve into the left ventricle, when the atrial septum was patent ${ }^{1}$ ( 30 patients).

1 Patent foramen ovale or atrial septal defect.
When the atrial septum was not crossed the catheter was passed into the left ventricle through the aortic valve from a femoral arteriotomy ( 33 cases). The only occasional complication noted after femoral arteriotomy has been absent pulsation of the femoral and distal arteries. When absent pulsation persisted for more than 12 hours the arteriotomy site was explored by our surgical colleagues, and balloon catheters passed into the artery both proximally and distally (Lincoln and Deverall, 1969). All patients in whom femoral arteriotomy was carried out had normal arterial pulses at the time of discharge from hospital.

The contrast medium used in all cases was 'Conray ' 480 ', a dose of $1.5 \mathrm{ml} / \mathrm{kg}$. being injected at such a pressure as to introduce all the medium into the left ventricle within approximately one second. When possible a cine film speed of 80 frames/sec. was used, but owing to technical problems a slower film (40-64 frames/ sec.) speed had to be used for some cases.

The positioning of the patient in relation to the $x$-ray beam is important, and it was found that a standard position could not be used. The plane of the interventricular septum could be seen in profile when viewed in the left anterior oblique projection in patients with normal right ventricular pressures. However, with right ventricular enlargement, associated with increased right ventricular pressure and an increased pulmonary blood flow, the plane of the interventricular septum lay more towards the coronal plane: for the septum then to be projected in profile the patient had to be turned further towards the true lateral position.

The plane of the interventricular septum may be judged by assessing the degree of right ventricular enlargement from the relative blood flow calculations and right ventricular pressure. Final assessment is made by careful observation of the appearances after the injection of a few millilitres of contrast medium when checking that the catheter tip lies free within the ventricular cavity. This was recorded on videotape, and immediately replayed several times.

A profile view of the interventricular septum was essential in order that contrast medium lying between the right ventricular trabeculae could be distinguished from small defects in the septum. The patient had to be rotated sufficiently to ensure that the descending aortic shadow was not superimposed on the interventricular septum. Failure to turn the patient sufficiently to allow a profile view of the septum can make it impossible to assess multiplicity of the septal defects. In two patients not included in this series the septum was not seen in profile and the defects in the septum could not be localized or enumerated precisely.

\section{Results and interpretation}

The diagnosis of a ventricular septal defect was confirmed when contrast medium passed anteriorly from the left ventricle into the right ventricle with subsequent opacification of the 
pulmonary artery. Commonly there was a single defect in the interventricular septum (54 patients). Multiple defects were seen in nine patients. The term 'multiple' denoted those instances in which contrast medium appeared to pass through the septum at more than one site.

The classification used for the location of the interventricular septal defect was: (i) high, where contrast medium passed anteriorly just below the semilunar valves (Fig. I); (ii) mid, where contrast medium passed anteriorly midway down the septum (Fig. 2); (iii) low, where contrast medium passed anteriorly near or at the apex of the right ventricle.

The number and location of the septal defects demonstrated by left ventricular cineangiocardiography are given in Table 3. No difficulty was experienced in defining and locating a single ventricular septal defect.

TABLE 3 Nature of interventricular septal 1 defect in 63 patients

$\begin{array}{lllr}\text { Single defects } & & & 54 \\ & \text { - } & \text { high } & 45 \\ & & \text { mid } & 4 \\ & - & \text { low } & 5 \\ \text { Multiple defects } & - & & 9\end{array}$

When multiple defects were suspected especial care was necessary in the interpretation of the film and certain points required attention. When the catheter was introduced through the mitral valve, reflux of contrast -medium through this valve sometimes occurred. It was almost always due to the presence wof the catheter in the valve orifice. In the oblique projection the lower border of the

TABLE 49 patients with multiple interventricular septal defects indicating associated cardiac lesion

\begin{tabular}{ll}
\hline Associated cardiac lesion & $\begin{array}{l}\text { No. of } \\
\text { patients }\end{array}$ \\
\hline $\begin{array}{l}\text { Ventricular septal defects } \\
\text { Ventricular septal defects with atrial }\end{array}$ & 3 \\
septal defect & 2 \\
$\begin{array}{l}\text { Ventricular septal defects with pulmonary } \\
\text { valve stenosis }\end{array}$ & I \\
$\begin{array}{l}\text { Ventricular septal defects with } \\
\text { coarctation }\end{array}$ & I \\
$\begin{array}{l}\text { Ventricular septal defects with banded } \\
\text { pulmonary artery }\end{array}$ & I \\
$\begin{array}{c}\text { Double outlet right ventricle with } \\
\text { pulmonary valve stenosis }\end{array}$ & I \\
\hline
\end{tabular}

left atrium lay midway down the interventricular septum. Reflux through the valve had to be distinguished from transit of contrast medium through a defect in the septum. When the angiocardiogram was carried out with the lungs in an expiratory phase the diaphragmatic shadow sometimes obscured the apex of the left ventricle and the lower part of the septum. Finally, when there was respiratory movement opacified pulmonary vessels sometimes gave the superficial impression of small low defects. Conditions in which multiple

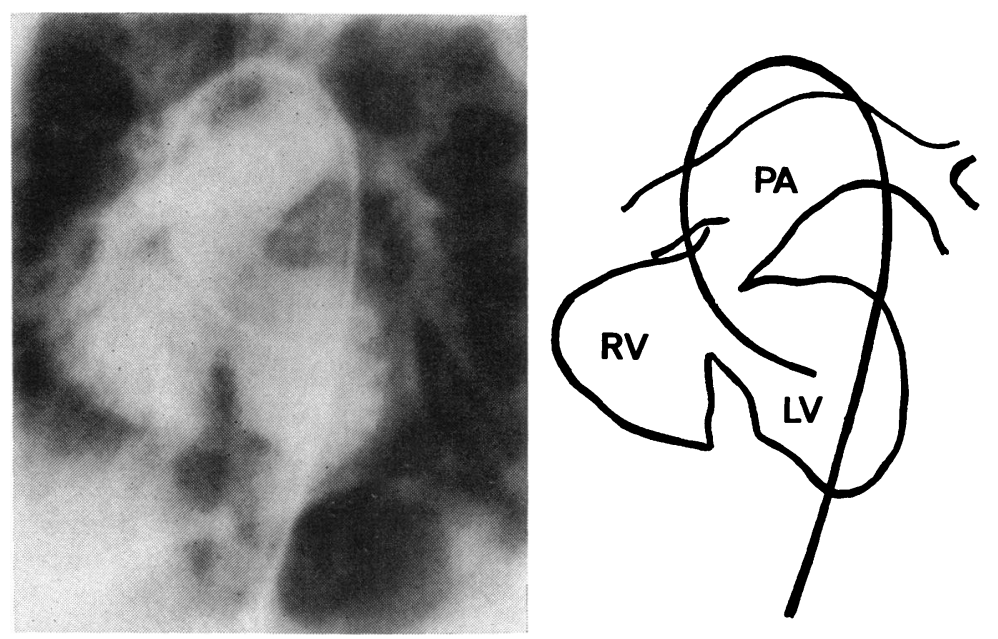

FIG. I $A$ defect high in the interventricular septum.

FIG. $2 A$ defect in the mid part of the interventricular septum.

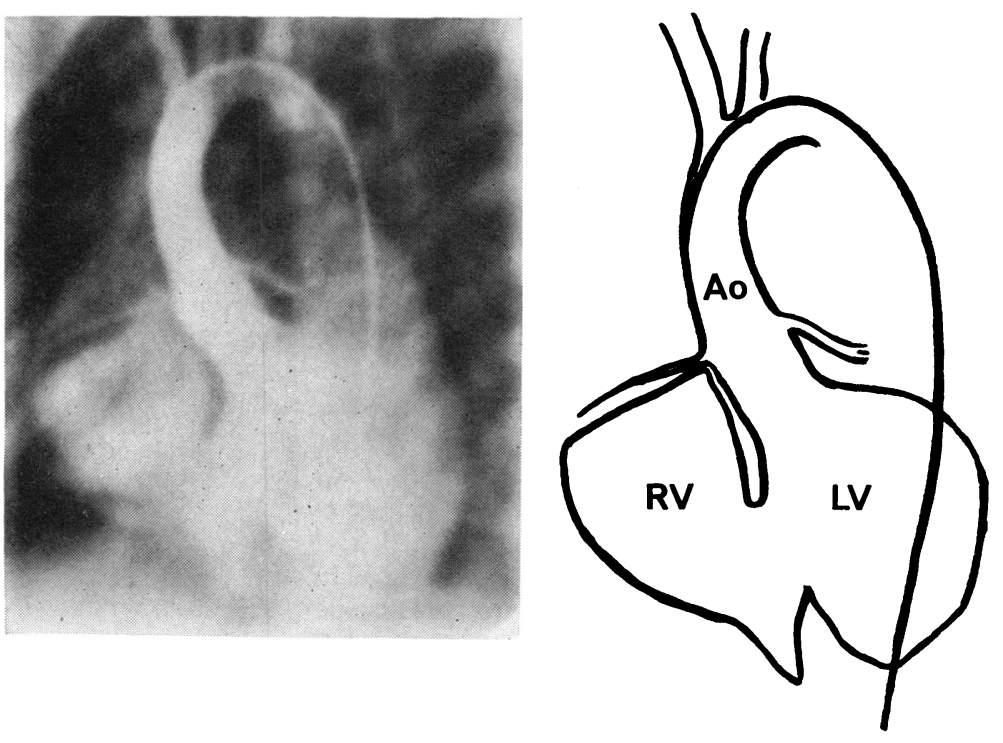


defects of the interventricular septum were encountered are given in Table 4.

\section{Accuracy of angiocardiographic findings}

Of the 63 patients, 28 have so far undergone operative correction of their defects. Of these patients, 22 had a single defect in the location indicated in the angiocardiogram; 6 had more than one defect at operation: in 4 of these the site and number of the defects had been correctly predicted from the angiocardiograms. Thus 2 patients who appeared to have a single defect were found to have multiple defects at operation: one of these patients had a second small defect adjacent to the site of the major defect, and the other patient had five defects all closely related to each other; when the area was viewed through the right ventriculotomy trabeculae were seen splitting the defect in the septum into five separate 'orifices'.

One patient had a single ventricular septal defect predicted from the cine-angiocardiogram, and one defect only was found at ventriculotomy. However, an aberrant papillary muscle passed from the right ventricle through the defect and was attached to the mitral valve. The angiocardiogram failed to show the presence of this aberrant muscle.

\section{Discussion}

The findings at operation have confirmed the theoretical advantages of the left ventricular cine-angiocardiogram in that no error of location of a septal defect has been encountered. Single septal defects were accurately defined by this technique. Multiple septal defects were accurately defined in patients in whom defects were separated by an appreciable distance. In two patients predicted to have a single defect multiple defects were seen when the septum was viewed through a right ventriculotomy: however, all the orifices were close to each other and they presented no problem at closure. For these reasons the left ventricular cine-angiocardiogram has become the chosen method of demonstrating defects in the interventricular septum.

Generally, patients studied have had shunts from the left ventricle to the right ventricle. However, a very few patients with either pulmonary stenosis or a banded pulmonary artery have had small right-to-left shunts across the septum. Even so the left ventricular cine-angiocardiogram has been successful in showing the septal defects. The visualization of the smooth anterior margin of the left ventricle has considerable advantages over the visualization of the irregular margin of the right ventricle, and septal defects can be seen more easily.

The technique shows the septal defects in the first two or three systoles after the start of injection of the contrast medium. A profile view of the septum is important, and it has been found that with increasing right ventricular enlargement the septum can come to lie in the coronal plane. Meticulous assessment of the patient's heart and of the positioning of the patient in relation to the $x$-ray beam is imperative if good results are to be consistently obtained. While it has been recognized that the ventricular septum lies quite commonly in the coronal plane in patients with defects in the septum, this position of the septum is also found in total anomalous pulmonary venous drainage, transposition of the great arteries, double outlet right ventricle, and occasionally in atrial septal defects.

The single plane left ventricular cineangiocardiogram has not proved particularly useful in defining anatomical lesions other than defects in the interventricular septum. No patient has been submitted to operation with this type of angiogram as the sole contrast medium study of the heart. Thus, the left ventricular cine-angiocardiogram is an important adjunct in the investigation of a defect in the interventricular septum.

Some authors such as Keith, Rowe, and Vlad (1967) have recorded a low incidence of multiple defects in the interventricular septum. However, others, namely Stark et al. (1970), have reported a very much higher incidence $(33 \%)$ of multiple ventricular septal defects in patients who have had serious symptoms from early life. Furthermore, such patients were found to have a much increased incidence of serious associated cardiovascular lesions. Complete surgical correction of the cardiac lesions is facilitated by a precise knowledge of the nature of all the defects.

We wish to thank Dr. R. E. Bonham-Carter for help and encouragement in preparing the study. We are particularly indebted to $\mathrm{Mr}$. D. J. Waterston, Mr. E. Aberdeen, and Mr. J. Stark for help with the surgical aspects. We are grateful to Dr. G. R. Graham for his helpful comments.

\section{References}

Björk, V. O. (1964). The transatrial approach to ventricular septal defect. fournal of Thoracic and Cardiovascular Surgery, 47, 178.

- (1965). Surgical treatment of ventricular septal defect. Thorax, 20, 278.

Cooley, D. A. (1959). Current status of surgical treatment of ventricular septal defect. Diseases of the Chest, 35, 65I. 
Garamella, J. J., Cruz, A. B., Heupel, W. H., Dahl, J. C., Jensen, N. K., and Berman, R. (1960). Ventricular septal defect with aortic insufficiency. Successful surgical correction of both defects by the transaortic approach. American fournal of Cardiology, 5, 266.

Gerbode, F., Hultgren, H., Melrose, D., and Osborn, J. (1958). Syndrome of left ventricular-right atrial shunt. Successful surgical repair of defect in five cases, with observation of bradycardia on closure. Annals of Surgery, 148, 433.

Gonzalez-Lavin, L., and Barratt-Boyes, B. G. (1969). Surgical considerations in the treatment of ventricular septal defect associated with aortic valvular incompetence. Fournal of Thoracic and Cardiovascular Surgery, 57, 422.

Hudspeth, A. S., Cordell, A. R., Meredith, J. H., and Johnston, F. R. (1962). An improved transatrial approach to the closure of ventricular septal defects. Fournal of Thoracic and Cardiovascular Surgery, 43, 157.

Kay, E. B., Rodriguez, P., and Zimmerman, H. A. (1965). Surgery for ventricular septal defect in dextroversion through a left ventriculotomy. American fournal of Cardiology, 15, 267.

Kay, J. H., Anderson, R. M., Tolentino, P., Dykstra, P., Shapiro, M. J., Meihaus, J. E., and Magidson, O. (1960). The surgical closure of high pressure ventricular septal defect through the right atrium. Surgery, 48, 65.

Keith, J. D., Rowe, R. D., and Vlad, P. (1967). Heart Disease in Infancy and Childhood, 2nd ed., p. 298. Macmillan, New York.
Lincoln, J. C. R., and Deverall, P. B. (1969). The treatment of arterial thrombosis in infants and children by balloon catheters. Fournal of Pediatric Surgery, 4, 359.

March, H. W., Ross, J. K., Weirich, W. L., and Gerbode, F. (196I). The influence of the ventriculotomy site on the contraction and function of the right ventricle. Circulation, $24,572$.

Muller, W. H., and Dammann, J. F. (1952). The treatment of certain congenital malformations of the heart by the creation of pulmonic stenosis to reduce pulmonary hypertension and excessive pulmonary blood flow. Surgery, Gynecology and Obstetrics, 95, 213.

Mustard, W. T. (196r). The operative closure of ventricular septal defects in childhood. Postgraduate Medical fournal, 37, 653.

Nicks, R., Cartmill, T., Clifton, B. S., Collison, J., and Grant, A. F. (1962). Surgery of ventricular septal defects. British Medical fournal, 1, 596.

Reynolds, J. L. (1966). Supracristal ventricular septal defect. American fournal of Cardiology, 18, 610.

Stark, J., Aberdeen, E., Waterston, D. J., BonhamCarter, R. E., and Tynan, M. (1969). Pulmonary artery constriction (banding): A report of 146 cases. Surgery, $65,808$.

-, Tynan, M., Aberdeen, E., Waterston, D. J., Bonham-Carter, R. E., Graham, G. R., and Somerville, J. (1970). Repair of intracardiac defects after previous constriction (banding) of the pulmonary artery. Surgery, 67, 536. 